\title{
Corticosteroids: do they damage the cardiovascular system?
}

\author{
Simon R.J. Maxwell, Robert J. Moots ${ }^{1}$ and Martin J. Kendall
}

\author{
Departments of Medicine and ${ }^{1}$ Rheumatology, Queen Elizabeth Hospital, Edgbaston, Birmingham \\ B15 2TH, UK
}

\begin{abstract}
Summary: Since their introduction for the treatment of rheumatoid arthritis, corticosteroids have become widely used as effective agents in the control of inflammatory diseases. Although there have been undoubted benefits upon mortality in diseases such as systemic lupus erythematosus, many patients survive only to suffer a high incidence of premature atherosclerosis. There is also evidence of increased rates of vascular mortality in other corticosteroid-treated diseases, such as rheumatoid arthritis, reversible airways obstruction and transplant recipients. Possible mechanisms of damage include elevated blood pressure, impaired glucose tolerance, dyslipidaemia, and imbalances in thrombosis and fibrinolysis. This paper reviews the clinical evidence supporting the contention that there is an excess cardiovascular mortality in steroid-treated patients and the underlying mechanisms, and points to further areas of research.
\end{abstract}

\section{Introduction}

Corticosteroids are comparable to endogenous glucocorticoids both in structure and function, they bind to the physiological glucocorticoid cytosolic receptor and influence DNA transcription in all parts of the body. Since they were introduced into British medical practice in 1948 for the treatment of rheumatoid arthritis (RA), the potent anti-inflammatory and immunosuppressive properties of corticosteroids have led to their use in a variety of rheumatic and other diseases. There is even a current debate as to whether such drugs should be prescribed more widely in RA. Even from the earliest days, it has been recognized that corticosteroid therapy is associated with many undesirable side effects but, since therapy was employed to control severe diseases with high morbidity and mortality, the risk of these complications was considered acceptable. However, today there are often alternatives to steroid therapy and the risk to benefit ratio of this class of drugs requires closer scrutiny before treatment is considered. The prognosis of systemic lupus erythematosus (SLE), for example, has greatly improved in the post-steroid era. However, despite a better prognosis for lupus-related complications, many patients survive only to suffer a high rate of

Correspondence: S.R.J. Maxwell, B.Sc., M.R.C.P. Accepted: 30 June 1994 premature cardiovascular complications, prompting us to question whether these events may be a consequence of therapy - in particular, prolonged treatment with oral corticosteroids.

Such a hypothesis deserves further analysis. The demonstration of increased cardiovascular disease due to corticosteroid therapy would have major implications for patients with a variety of other less pernicious diseases sometimes controlled by steroids, such as mild RA. In this article, we discuss the evidence that corticosteroids induce vascular damage and highlight the mechanisms that might underlie this association by linking our current understanding of the actions of glucocorticoids with the pathophysiology of vascular disease.

\section{Evidence for steroid-related damage}

The potential problems and benefits of steroid therapy can be assessed by examining its impact on morbidity and survival in chronic steroidresponsive diseases (Table I).

The outlook for patients with SLE has improved greatly during the last few decades since the introduction of corticosteroids. The survival rate has risen from less than $50 \%$ at 4 years in the early $1950 \mathrm{~s},{ }^{1}$ to more tha $70 \%$ at 10 years by $1980^{2}$ and has continued to improve. The improved survival has been parallelled by an increased usage of 
corticosteroids, although earlier diagnosis of SLE, together with improvements in nephrology services, antibiotics and anti-hypertensive agents are likely to have had some influence on these figures. In 1976, Urowitz and colleagues noted a bimodal distribution of mortality amongst their series of 81 patients with SLE. ${ }^{3}$ The early deaths in six patients were primarily due to active lupus or intercurrent infection: whereas the late deaths were primarily due to atherosclerotic cardiovascular disease, in the absence of active disease. This finding prompted the question as to whether atherosclerosis of the coronary arteries is a particular problem in patients with SLE and, if so, how is atherogenesis facilitated?

Several authors have produced anecdotal reports of premature atherosclerotic myocardial infarction in patients with SLE. ${ }^{4-9}$ In one cohort of 133 SLE patients followed up for 6 years, as many as eight myocardial infarctions occurred, including two in young women. ${ }^{10}$ This compared with an anticipated infarct occurrence of 0.87 . Furthermore, those sustained cardiac events had used corticosteroids for an average $81 \%$ of the study duration compared with $46 \%$ amongst the rest of the group.

In a large study of 552 patients, Ginzler and Berg $^{11}$ found that as many as $10 \%$ of deaths were due to myocardial infarction, and others could have occurred as a consequence of atheroma, such as dissecting aortic aneurysm and cerebrovascular accidents. Accelerated, non-fatal atherosclerosis was also suggested by the finding of 45 cases of angina or myocardial infarction in a follow-up of 507 SLE patients. ${ }^{12}$ Amongst these, three premenopausal women required coronary artery bypass surgery.

Various anatomical studies of the coronary circulation have been performed. Necropsies in 36 corticosteroid-treated patients were compared with specimens from the presteroid era: ${ }^{13}$ it was observed that the lumen of at least one major coronary vessel was narrowed more than $50 \%$ by atherosclerotic plaques in nearly a half of the cases receiving corticosteroids for more than a year, and none of the cases on steroids for less than a year. The authors pointed out that coronary atheroma was rarely described in the presteroid necropsies. A study of 2,856 necropsies performed on young Japanese found that those with collagen diseases including SLE had more severe atheroma especially in the second decade. ${ }^{14}$ Atheroma also appears to be more common in SLE patients than controls at angiography. ${ }^{15}$

\section{Steroid damage in other rheumatic diseases}

If corticosteroids have an adverse effect on the cardiovascular system in SLE, does the same phenomenon occur in other steroid-treated illness? After the publication of the first trials of therapy in RA, ${ }^{16}$ corticosteroids became popular for disease suppression. Some authors are trying to rekindle a greater enthusiasm for their use. ${ }^{17}$

Mortality in RA has been the subject of a number of recent studies. Scott et al.$^{18}$ followed 112 RA cases at one centre over 20 years, by which time 37 had died. Nearly a third of the deaths were ascribed to cardiovascular disease and the authors suggested that this may have been due to steroids. Mutru et al. ${ }^{19}$ used a case-control technique to follow 1,000 cases of RA over 10 years. During that time, 352 cases and 221 controls died, with a significantly greater incidence of cardiovascular mortality amongst cases compared to controls. A number of other studies have also reported an increased incidence of cardiac deaths in RA. ${ }^{20-23}$ An effect of corticosteroids on the heart in RA is also implied by a report of an increased incidence of electrocardiographic (ECG) abnormalities in patients on low-dose steroids when compared to non-steroid treated controls. ${ }^{24}$ This group found ST and $T$ wave abnormalities five times more frequent in those controlled on steroids. Peripheral vascular disease was also found to be considerably more common in a corticosteroid-treated group $(60 \%)$ than a group of controls $(20 \%) .{ }^{25}$ Necrops $B$ studies of patients with RA have also noted a high incidence of coronary disease. ${ }^{26,27}$

\section{Steroids and non-rheumatic disease}

Corticosteroids became widely available in 1955 for use in the treatment of reversible airways obstruction and remain effective in controlling airway inflammation. Robinette and Fraumeni ${ }^{28}$ examined the 'all cause' mortality over a 29 -year period in a cohort of 9,550 war veterans hospitalized with asthma during 1944-1945. When compared with a control group hospitalized at the same time with 'acute nasopharyngitis' the relative risk of death from ischaemic heart disease was 1.46 $(P<0.001)$ and from stroke was $1.51(P<0.05)$.

Table I Steroid-responsive diseases

Systemic lupus erythematosus

Rheumatoid arthritis

Graft rejection post-transplantation

Asthma

Sarcoidosis

Inflammatory bowel disease

Nephrotic syndrome

Polyarteritis nodosa

Wegner's granulomatosis

Temporal arteritis/polymyalgia rheumatica 
The authors were unable to offer a good explanation for this interesting finding.

Corticosteroids have been widely employed in transplant units as immunosuppressive agents. Recipients of heart transplants are at risk of graft failure as a result of accelerated coronary atherosclerosis, although the aetiology of this problem remains unclear. Becker et al. ${ }^{29}$ noted a high incidence of dyslipidaemia amongst their transplant patients and showed by linear regression analysis that cumulative prednisone dosage was the strongest predictor of both total and low density lipoprotein levels. Renal transplant patients are also at increased risk of developing atherosclerosis. Kariska $^{30}$ reported that the incidence of vascular disease in a series of renal transplant recipients was significantly related to the number of acute rejection episodes, all treated with high doses of corticosteroids.

\section{Steroids and peripheral vascular disease}

Most of the studies relating corticosteroids to the incidence of cardiovascular disease have focused on myocardial infarction, although the steroid effect may not be restricted to coronary arteries. Amongst cases of RA, atherosclerosis of the peripheral arteries was three times as common in those treated with corticosteroids as those who were not. ${ }^{25}$ Other studies have implied that cerebrovascular events may be associated with corticosteroid treatment. The reports on mortality in RA by Mutru et al. ${ }^{19}$ and Reilly et al. ${ }^{31}$ both point to an increase in the incidence of stroke. The Oxford Community Stroke Project, ${ }^{32}$ recorded the fact that at least nine of their cases of first stroke were currently or recently treated with steroids for presumed arteritic diseases. The West Birmingham Stroke Project found the relative risk of stroke to be 6.4 in those who reported that they had been regular users of oral corticosteroids during the year preceeding their stroke..$^{33}$

Finally, the endogenous overproduction of glucocorticoids, Cushing's syndrome, is also known to be associated with premature atherosclerosis and death from myocardial infarction and stroke. ${ }^{34}$ Data from animal models also support a role for glucocorticoids in accelerating atherogenesis. ${ }^{35}$ Both cortisone and adrenocorticotrophic hormone (ACTH) are capable of causing vascular injury ${ }^{36}$ and glucocorticoids have been also shown to promote direct endothelial cell damage. ${ }^{37}$

\section{Mechanisms of steroid-induced vascular damage}

If corticosteroid administration is a risk factor for cardiovascular disease, how is the damage mediat- ed? Knowledge of the method of action of steroids has grown rapidly over the last few years, providing greater understanding of both beneficial and unwanted effects. Some of these actions might be seen as harmful to heart and circulation (Table II) and will be reviewed in more detail.

\section{Hypertension}

Hypertension was one of the features of Cushing's original report of endogenous hypercortisolism ${ }^{38}$ and there is still widespread acceptance that high blood pressure is a sequel of glucocorticoid excess from whatever cause. ${ }^{39}$ Several studies have suggested that long-term low-dose corticosteroid therapy can cause hypertension. ${ }^{40-43}$ Beevers et al.$^{44}$ found a highly significant rise in systolic blood pressure $(135.9$ to $147.0, P<0.001)$ in 195 patients with either asthma or RA treated for at least one year with prednisone or prednisolone compared to those not on steroids.

\section{Insulin resistance}

Glucocorticoid excess causes insulin resistance, ${ }^{45,46}$ mediated by a reduced affinity of insulin receptors, ${ }^{47,48}$ which produces a tendency towards hyperglycaemia and hyperinsulinaemia. Thus even mild corticosteroid-induced diabetes may have many of the adverse effects on the cardiovascular system traditionally associated with the typical type II hyperinsulinaemia per se as a risk factor for coronary artery disease $\mathrm{e}^{50-53}$ and this may also be true of children and premenopausal women. ${ }^{54,55}$

\section{Effects of lipid metabolism}

Disturbances of blood lipid levels following corticosteroid treatment have been well documented. ${ }^{29,56-59}$

Table II Possible mechanisms contributing to corticosteroid-induced vascular damage
Hypertension
Hypercholesterolaemia
Hypertriglyceridaemia
Insulin resistance
Hyperinsulinaemia
Obesity
Electrolyte disturbances
Avascular necrosis
Hypercoagulability
Endothelial-platelet balance disturbed
Endothelial cell damage
Catecholamine potentiation
Monocyte-macrophage function
Corticosteriod cytotoxicity
Corticosteriod vasculitis 
The most usual finding is a rise in low-density lipoprotein cholesterol and to a lesser extent, very low-density lipoprotein cholesterol. Both changes might be expected to affect the risk of coronary disease adversely. ${ }^{60}$ Studies on patients with SLE suggest the overall levels of apolipoprotein Bcontaining particles were greater in those treated with prednisone. ${ }^{61}$

The corticosteroids are also amongst several hormones capable of stimulating 'hormone-sensitive' tissue lipase, possibly by potentiating the effects of catecholamines ${ }^{62}$ and leading to an overall increase in availability of circulating fatty acids, which may also be harmful to the heart.

\section{Obesity}

There is a well-established relationship between hypercortisolism and obesity both in man and experimental animals. ${ }^{63-65}$ This association is also seen with corticosteroid therapy. ${ }^{66,67}$ Patients with Cushing's syndrome tend to exhibit obesity with a characteristic deposition of fat in the upper body. ${ }^{38}$ Altered distribution of adipose tissue has also been reported in patients treated with corticosteroids, particularly in the upper body ${ }^{68}$ The distribution of excess body fat seems to be a significant factor in relation to cardiovascular disease (reviewed by Kaplan ${ }^{69}$ ). There appear to be two distinct patterns: central (upper body, male, android) obesity with waist/hip ratio greater than 0.85 or peripheral (female, gynoid) pattern with waist/hip ratio less than 0.85 . There is considerable evidence that, at a given weight, individuals with central obesity have an increased risk of cardiovascular disease. ${ }^{70-74}$ This group also have higher blood pressures, serum triglycerides and glucose, peripheral insulin resistance and hyperinsulinaemia, and lower highdensity lipoprotein levels. ${ }^{75-79}$

\section{Avascular necrosis of bone}

This phenomenon is known to be associated with the use of corticosteroids and seems to result from a disruption of the vascular supply of the femoral head. ${ }^{80}$ The association was noted by Zizic et al ${ }^{81}$ who documented Cushingoid changes in $86 \%$ of patients with SLE with avascular necrosis and only $15 \%$ of SLE patients without avascular necrosis $(P<0.0001)$. The duration of steroid therapy ${ }^{82}$ the total cumulative dose ${ }^{83}$ or the highest daily dosage ${ }^{84}$ have all been implicated as relevant factors.

Several causes for avascular necrosis have been proposed but altered vascular function seems to be the most likely. Some authors pointed to the induction of a hypercoagulable state by corticosteroid ${ }^{85-87}$ suggesting that microvascular clots may cause local ischaemia. Another popular theory is that corticosteroids can induce fat emboli, which obstruct the subchondral arterioles. ${ }^{88-91}$ Indeed, Fisher and Bickel ${ }^{92}$ had reported fat emboli in the subchondral arterioles of up to half of the specimens examined.

\section{The coagulation system}

Several reports have suggested that corticosteroids produce a state of hypercoagulability ${ }^{85,86}$ manifested as a shortening of the activated partial thromboplastin time ${ }^{87}$ (Table III). This finding is significant since occlusive thrombus formation is likely to be the final event leading to acute myocardial infarction or ischaemic stroke.

The potential effect of corticosteroids on fibrinogen deserve particular mention. Fibrinogen is now emerging as a major risk factor in stroke $\mathrm{e}^{93}$ and myocardial infarction, ${ }^{94-97}$ and may be a closer predictor of cardiovascular death than serum cholesterol. ${ }^{98}$ Fibrinogen, an acute phase protein is produced in the liver. In vitro cultured rat liver cells will increase the synthesis of fibrinogen mRNA when incubated with glucocorticoids.$^{99}$ Fibrinogen production has been shown to increase in response to glucocorticoids both in vitro ${ }^{100-102}$ and in vivo. ${ }^{103,104}$

The natural defence to fibrin deposition and clot formation is the fibrinolytic system, initiated bo tissue plasminogen activator. Although there are no studies of the overall changes in fibrinolytio activity in response to corticosteroids, cellula production of plasminogen activator by both the mouse macrophage and human neutrophil is blocked by corticosteroids. ${ }^{105,106}$ Clearly this aspect of glucocorticoid activity may be crucial to intravascular pathology and requires further investigation.

There is further potential for corticosteroids to cause disruption of the thrombosis-fibrinolysis balance by their effects on limiting the availability of arachidonic acid for prostacyclin synthesis in the vascular wall. ${ }^{107,108}$ Glucocorticoids stimulate DNA transcription to produce lipocortin, a protein that inhibits phospholipase A2. ${ }^{109-114}$ This prevents the formation of products of both the cyclooxygenase and lipoxygenase systems, including prostaglandins, prostacyclin, leukotrienes and thromboxanes. It would appear that there is a proportionally

Table III Factors contributing to a steroid-induced hypercoagulability

Increased cellular production of fibrinogen

Reduced cellular plasminogen activator formation

Inhibition of phospholipase A2 formation and arachidonic acid release - prostacyclin/thromboxane imbalance 
greater inhibition of prostacyclin synthesis by glucocorticoids than the thromboxanes ${ }^{115,116}$ and this occurs at therapeutic doses. ${ }^{117}$ A relative deficiency of prostacyclin may allow dominance of platelet thromboxanes at the endothelial surface and favour vasoconstriction, thrombus formation and release of platelet-derived growth factors stimulating local cellular proliferation and atheroma. Some have advocated the simultaneous use of anti-platelet agents, such as aspirin concurrently with corticosteroids, in an attempt to restore the balance. ${ }^{118}$

\section{Leucocyte function}

The egress of monocytes from the vascular lumen and eventual uptake of lipid deposits seems to underly the atherosclerotic process. ${ }^{119,120}$ Glucocorticoids inhibit the responsiveness of tissue macrophages to cytokines, depress bactericidal activity and prevent normal chemotaxis. ${ }^{121-123}$ If the failure to complete the phagocytic process adequately included other materials such as lipids, one could envisage that the transition from tissue scavenger to lipid laden 'foam' cell might be facilitated.

\section{Conclusions}

In view of their adverse effects on a number of cardiovascular risk factors, it is surprising that a possible relationship between corticosteroid usage and cardiovascular damage has not been more thoroughly investigated. A considerable body of evidence has been presented that, at the very least, casts suspicion about the effects of the agents currently in widespread use. The lack of attention previously given to this subject probably reflects the fact that therapy is usually given to those of older age who are already prone to the high incidence of age-related atheroma or to younger patients with serious multi-system diseases often involving widespread vasculitis. Under these circumstances a small but genuine effect could be masked.

In summary, there is good evidence in the literature to support the contention that regular systemic treatment with corticosteroids is associated with an increase in the incidence of major cardiovascular disease. Several mechanisms may predispose corticosteroid users to an increased risk of atherosclerosis and thrombosis and further research is required to test this hypothesis. As physicians we are obliged to consider the situation and the therapeutic options carefully before starting our patients on long-term steroid therapy.

It is hoped that, in the future, safer and less toxic steroid-sparing agents will be available. In the mean time, although steroids may have a lifesaving role in general diseases, their dosage should be reviewed regularly by prescribers to lessen the subsequent complications of long-term therapy.

\section{References}

1. Merrill, M. \& Shulman, L.E. Determination of prognosis in chronic disease, illustrated by systemic lupus erythematosus. $J$ Chron Dis 1955, 1: 12-32.

2. Ginzler, E.M., Diamond, H.S., Weiner, M. et al. A multicentre study of outcome in systemic lupus erythematosus. I. Entry variables as predictors of prognosis. Arthritis Rheum 1982, 25: 601-611.

3. Urowitz, M.B., Bookman, A.A.M., Koehler, B.E., Gordan, D.A., Smythe, H.A. \& Ogryzlo, M.A. The bimodal mortality pattern of systemic lupus erythematosus. Am J Med 1976, 60: $221-225$.

4. Karsh, J., Klippel, J.H., Balow, J.A. et al. Mortality in lupus nephritis. Arthritis Rheum 1979, 22: 764-769.

5. Mejia, G., Zimmerman, S.W., Glass, N.R. et al. Renal transplantation in patients with systemic lupus erythematosus. Arch Intern Med 1983, 143: 2089-2092.

6. Jensen, G. \& Sigard, B. Systemic lupus erythematosus and acute myocardial infarction. Chest 1973, 64: 653-654.

7. Tsakraklides, V.G., Blieden, L.C. \& Edwards, J.E. Coronary atherosclerosis and myocardial infarction associated with systemic lupus erythematosus. Am Heart $J$ 1974, 87: 637-641.

8. Meller, J., Conde, C.A., Deppisch, L.M., Donoso, E. \& Dack, S. Myocardial infarction due to coronary atherosclerosis in three young men with systemic lupus erythematosus. Am J Cardiol 1975, 35: 309-314.

9. Asakura, Y., Nakamoto, S., Nishikawa, Y. et al. A case of myocardial infarction in a young man with systemic lupus erythematosus. Kokyo To Junkan 1992, 40: 495-498.
10. Jonsson, H., Nived, O. \& Sturfelt, G. Outcome in systemic lupus erythematosus: a prospective study of patients from a defined population. Medicine 1989, 68: 141-150.

11. Ginzler, E.M. \& Berg, A. Mortality in systemic lupus erythematosus. J Rheumatol 1987, 14 (Suppl 13): 218-222.

12. Gladman, D.D. \& Urowitz, M.B. Mortality in systemic lupus erythematosus. J Rheumatol 1987, 14 (Suppl 13): 223-226.

13. Bulkey, B.H. \& Roberts, W.C. The heart in systemic lupus erythematosus and the changes induced in it by corticosteriod therapy. Am J Med 1975, 58: 243-264.

14. Tanaka, K., Masuda, J., Imamura, T. et al. A nationwide study of atherosclerosis in infants, children and young adults in Japan. Atherosclerosis 1988, 72: 143-156.

15. Homcy, C.J., Liberthson, R.R., Fallon, J.T., Gross, S. \& Miller, L.M. Ischaemic heart disease in systemic lupus erythematosus in the young patient: report of six cases. Am J Cardiol 1982, 49: 478.

16. Copeman, W.S.C., Savage, O., Bishop, P.M.F., Dodds, E.C., Gottlieb, B. \& Glynn, J.H.H. A study of cortisone and other steriods in rheumatoid arthritis. $\mathrm{Br} M e d J$ 1950, ii: 849-855.

17. Myles, A. Corticosteriod treatment in rheumatoid arthritis. Br J Rheumatol 1985, 24: 125-127.

18. Scott, D.L., Symmons, D.P.M., Coulton, B.L. \& Popert, A.J. Long-term outcome of treating rheumatoid arthritis: results after 20 years. Lancet 1987, i: 1108-1111. 
19. Mutru, O., Laakso, M., Isomaki, H. \& Koota, K. Ten year mortality and causes of death in patients with rheumatoid arthritis. Br Med J 1985, 290: 1797-1799.

20. Rasker, J.J. \& Cosh, J.A. Cause and age at death in a prospective study of 100 patients with rheumatoid arthritis. Ann Rheum Dis 1981, 40: 115-120.

21. Prior, P., Symmons, D.P.M., Scott, D.L., Brown, R. \& Hawkins, C.F. Cause of death in rheumatoid arthritis. $\mathrm{Br} \mathrm{J}$ Rheumatol 1984, 23: 92-99.

22. Allebeck, P. Increased mortality in rheumatoid arthritis. Scand J Rheumatol 1982, 11: 81-86.

23. Monson, R.R. \& Hall, A.P. Mortality among arthritics. $J$ Chronic Dis 1976, 29: 459-467.

24. Ishikawa, Y., Togushi, T., Kawagoe, M., Saito, E., Abe, T. \& Homma, M. ECG abnormalities in steroid-treated rheumatoid patients. Lancet 1977 , ii: 828 .

25. Kalbak, K. Incidence of arterioclerosis in patients with rheumatoid arthritis receiving long-term corticosteriod therapy. Ann Rheum Dis 1972, 31: 196-200.

26. Berntsen, C.A. \& Freyberg, R.H. Rheumatoid patients after five or more years of corticosteriod treatment: a comparative analysis of 183 cases. Ann Intern Med 1961, 54: 938-953.

27. Brooks, P.M., Stephens, W.H., Stephens, M.E.B. \& Buchanan, W.W. How safe are anti-rheumatic drugs? A study of possible iatrogenic deaths in patients with rheumatoid arthritis. Health Bull (Edin) 1975, 33: 108-111.

28. Robinette, C.D. \& Fraumeni, J.F. Asthma and subsequent mortality in world war II veterans. J Chron Dis 1978, 31: 619-624.

29. Becker, D.M., Chamberlain, B., Swank, R. et al. Relationship between corticosteroid exposure and plasma lipid levels in transplant recipients. Am J Med 1988, 85: 632-638.

30. Karsiske, B.L. Risk factors for accelerated atherosclerosis in renal transplant recipients. Am J Med 1988, 84: 985-992.

31. Reilly, P.A., Cosh, J.A., Maddison, P.J., Rasker, J.J. \& Silman, A.J. Mortality and survival in rheumatoid arthritis: a 25 year prospective study of 100 patients. Ann Rheum Dis 1990, 49: 363-369.

32. Sandercock, P.A.G., Warlow, C.P., Jones, L.N. \& Starkey, I.R. Predisposing factors for cerebral infarction: the Oxfordshire community stroke project. Br Med J 1989, 298: 75-80.

33. Shinton, R., Maxwell, S., Sagar, G. \& Beevers, D.G. Steroids, hypertension and stroke: the West Birmingham Stroke Project. Communication to British Hypertension Society, September 1990.

34. Christy, N.P. Cushing's syndrome: the natural history. In: Christy, N.P. (ed.) The Human Adrenal Cortex. Harper \& Row, New York, 1971, pp. 359-394.

35. Rosenfeld, S., Marmorstone, J., Sobel, H. \& White, A.E. Enhancement of experimental atherosclerosis in the dog. Proc Soc Exp Biol Med 1960, 103: 83-86.

36. Stamler, J., Pick, R. \& Katz, L.N. Effect of cortisone, hydrocortisone and corticotrophin on lipaemia, glycaemia and atherogenesis in cholesterol-fed chicks. Circulation 1954, 10: 237-246.

37. Bjorkerud, S. Effect of adrenocortical hormones on integrity of rat aortic endothelium. In: Schettler, G. \& Weizel, A. (eds) Atherosclerosis III; Proceedings of the Third International Symposium. Springer-Verlag, Berlin, 1974, pp. 245-249.

38. Cushing, $H$. The basophil adenomas of the putuitary body and their clinical manifestations (pituitary basophilism). Bull Johns Hopkins Hosp 1932, 50: 137.

39. Krakoff, L.R. Glucocorticoid excess syndromes causing hypertension. Cardiol Clin 1988, 6: 537-545.

40. Savage, O., Copeman, W.S.C., Chapman, L., Weils, M.V.\& Treadwell, B.L.J. Pituitary and adrenal hormones in rheumatoid arthritis. Lancet 1962, i: 232-235.

41. Treadwell, B.L.J., Sever, E.D., Savage, O. \& Copeman, W.S.C. Side-effects of long-term treatment with corticosteroids and corticotrophin. Lancet 1964, i: 1121.

42. Smyllie, H.C. \& Connolly, C.K. Incidence of serious complications of corticosteroid therapy in respiratory disease. Thorax 1968, 23: 571-581.
43. Thomas, T.P.L. The complications of systemic corticosteroid therapy in the elderly. Gerontology 1984, 30: 60-65.

44. Jackson, S.H.D., Beevers, D.G. \& Myers, K. Does longterm low-dose corticosteriod therapy cause hypertension? Clin Sci 1981, 61: 381S-383S.

45. Froesch, R.E., Winegrad, A.I., Renold, A.E. \& Thorn, G.W. Mechanism of glycosuria produced by administration of steroids with glucocorticoid activity. J Clin Invest 1958 36: 524.

46. Schubert, G.E. \& Schulz, H.D. Contribution to the clinica picture of steroid diabetes. Deutsch Med Wochenschr 1963, 8: $1175-1188$.

47. Goldfine, J.D., Kahn, C.R., Neville, D.M., Roth, J., Garrison, M.M. \& Bates, R.W. Decreased binding of insulin to its receptors in rats with hormone-induced resistance. Biochem Biophys Res Comm 1973, 53: 852-857.

48. Flier, J.S., Khan, C.R. \& Roth, J. Receptors, antireceptor antibodies and mechanisms of insulin resistance. $N$ Engl Med 1979, 300: 413-419.

49. Keen, H. Glucose intolerance, diabetes mellitus and atherosclerosis; prospects for prevention. Postgrad Med J 1976, 52: 445-451.

50. Pyorala, K. Relationship of glucose tolerance and plasma insulin to coronary heart disease from two population studies in Finland. Diabetes Care 1979, 2: 131-141.

51. Ducimetiere, P., Eschwege, E., Papoz, L., Richard, J.L., Claude, J.R. \& Rosselin, G. Relationship of plasma insulin levels to the incidence of myocardial infarction and coronary heart disease mortality in a middle-aged population. Diabetologia 1980, 19: 205-210.

52. Orchard, T.J., Becker, D.J., Bates, M., Kuller, L.H. \& Drash, A.L. Plasma insulin and lipoprotein concentrations: an atherogenic association? Am J Epidemiol 1983, 118, 326-337.

53. Welborn, T.A. \& Wearne, K. Coronary heart disease incidence and cardiovascular mortality in Busselton witks. reference to glucose and insulin concentrations. Diabete Care 1979, 2: 154-160.

54. Burke, G.L., Webber, L.S., Srinivasan, S.R., Radhakrishnamurthy, B., Freedman, D.S. \& Berenson, G. Fasting plasma glucose and insulin levels and their relationship to cardiovascular risk factors in children: the Bogalusa Heart Study. Metabolism 1986, 35: 441-446.

55. Wing, R.R., Bunker, C.H., Kuller, L.H. \& Matthews, K.A Insulin, body mass index, and cardiovascular risk factors in pre-menopausal women. Arteriosclerosis 1989, 9: 479-484.

56. Aldersberg, D., Schaefer, L. \& Drachman, S.R. Develop ment of hypercholesterolaemia during cortisone and ACTH therapy. JAMA 1950, 144: 909-914.

57. Bagdade, J.D., Porte, D. \& Bierman, E.L. Steroid-induced lipemia. Arch Intern Med 1970, 125: 129-134.

58. Zimmerman, J., Fainaru, M. \& Eisenberg, S. The effects of prednisone therapy on plasma lipoproteins and apolipoproteins. A prospective study. Metabolism 1984, 33: $521-526$.

59. Ettinger, W.H., Klinefelter, H.F. \& Kwitreovitch, P.O Effect of short-term, low-dose corticosteriods on plasma lipoprotein lipids. Atherosclerosis 1987, 63: 167-172.

60. Castelli, W.P. Cholesterol and lipids in the risk of coronary artery disease - the Framingham Heart Study. Can J Cardiol 1988, 4 (Suppl. A): 5 a

61. Ettinger, W.H. \& Hazzard, W.R. Elevated apolipoprotein-B levels in corticosteriod-treated patients with systemic lupus erythematous. J Clin Endocrinol Metab 1988, 67: 425-428.

62. Durrington, P.N. Hyperlipidaemia: Diagnosis and Management. Wright, London, 1989.

63. Strain, G.W., Zumoff, B., Strain, J.J., Levin, J. \& Fukushima, D.K. Cortisol production in obesity. Metabolism 1980, 29: 980-985.

64. Yikmura, Y., Bray, G.A. \& Wolfsen, A.R. Some effects of adrenalectomy in the fatty rat. Endocrinology 1978, 103: 1924-1928. 
65. Bruce, B.K., King, B.M., Phelps, G.R. \& Veitia, M.C. Effects of adrenalectomy and corticosterone administration on hypothalamic obesity in rats. Am J Physiol 1982, 243: E152-E157.

66. Berdanier, C.D. Role of glucocorticoids in the regulation of lipogenesis. FASEB J 1989, 3: 2179-2183.

67. Hollifield, G. Glucocorticoid-induced obesity - a model and a challenge. Am J Clin Nutr 1968, 21: 1471-1474.

68. Horber, F.F., Zurcher, R.M., Herren, H., Crivelli, M.A. Robotii, G. \& Frey, F.J. Altered body fat distribution in patients with glucocorticoid treatment and in patients on long-term dialysis. Am J Clin Nutr 1986, 43: 758-769.

69. Kaplan, N.M. The deadly quartet. Upper body obesity, glucose intolerance, hypertriglyceridaemia, and hypertension. Arch Intern Med 1989, 149: 1514-1520.

70. Donahue, R.P., Abbott, R.D., Bloom, E., Reed, D.M. \& Yano, K. Central obesity and coronary artery disease in men. Lancet 1987, i: 821-824.

71. Larsson, B., Svardsudd, K., Welin, L., Wilhelmsen, L., Bjorntorp, P. \& Tibblin, G. Abdominal adipose tissue distribution, obesity and risk of cardiovascular death: 13 year follow-up of participants in the study of men born in 1913. Br Med J 1984, 288: 1401-1404.

72. Lapidus, L., Bengtsson, C., Larsson, B., Pennert, K., Rybo, E. \& Sjostrom, L. Distribution of adipose tissue and risk of cardiovascular disease and death: a 12 year follow-up of participants in the population study of women in Gothenburg, Sweden. Br Med J 1984, 289: 1257-1261.

73. Ducimetiere, P., Richard, J. \& Cambien, F. The pattern of subcutaneous fat distribution in middle-aged men and the risk of coronary artery disease: The Paris Prospective Study. Int $J$ Obesity 1986, 10: 229-240.

74. Hatz, A.J., Rupley, D.C. \& Rimm, A.A. The association of girth measurements with disease in 32,856 women. $A m ~ J$ Epidemiol 1984, 119: 71-80.

75. Peiris, A.N., Mueller, R.A., Smith, G.A., Struve, M.F. \& Kissebah, A.H. Splanchnic insulin metabolism in obesity. Influence of fat distribution. $J$ Clin Invest 1986, 78: $1648-1657$

76. Peiris, A.N., Sothmann, M.S., Hoffmann, R.G. et al. Adiposity, fat distribution and cardiovascular disease. Ann Intern Med 1989, 110: 867-872.

77. Haffner, S.M., Fong, D., Hazuda, H.P., Pugh, J.A. \& Patterson, J.K. Hyperinsulinaemia, upper body obesity, and cardiovascular risk factors in non-diabetics. Metabolism 1988, 37: 338-345.

78. Foster, C.J., Weinsier, R.L., Birch, R. \& Norris, D.J. Obesity and serum lipids: an evalution of relative contribution of body fat and fat distribution to lipid levels. Int $J$ Obesity 1987, 11: 151-161.

79. Krotkiewski, M., Bjorntorp, P., Sjostrom, L. \& Smith, U. Impact of obesity on metabolism in men and women. J Clin Invest 1983, 72: 1150-1162.

80. Dubois, E.L. Avascular (aseptic) bone necrosis associated with SLE. In: Dubois, E.L. (ed.) Lupus Erythematosus. USC Press, Los Angeles, 1974, pp. 332-342.

81. Zizic, T.M., Marcoux, C., Hungerford, D.S. et al. Corticosteroid therapy associated with ischaemia necrosis of bone in systemic lupus erythematosus. Am J Med 1985, 79: 596-604.

82. Hurley, R.M., Steinberg, R.H., Patriquin, H. et al. Avascular necrosis of the femoral head in childhood systemic lupus erythematosus. Can Med Assoc J 1974, 111: 781-784.

83. Bergstein, J.M., Wiens, C., Fish, A.J. et al. Avascular necrosis of bone in systemic lupus erythematosus. $J$ Pediatr 1974, 85: 31-35.

84. Abeles, M., Urman, J.D. \& Rothfield, M.F. Aseptic necrosis of bone in systemic lupus erythematosus. Relationship to corticosteriod therapy. Arch Intern Med 1978, 138: $750-754$.

85. Cosgriff, W.W. Thromboembolic complications associated with ACTH and cortisone therapy. JAMA 1951, 147: 924-926.
86. Goldie, I., Tibblin, G. \& Scheller, S. Systemic lupus erythematosus and aspectic bone necrosis. Acta Med Scand 1967, 182: 55-63.

87. White, G.C., Marder, V.J., Colman, R.W., Hirsh, J. \& Salzman, E.W. Approach to the bleeding patient. In Colman, R.W., Hirsh, J., Marder, V.J. \& Saltzman, E.W. (eds) Hemostasis and Thrombosis. Lippincott, Philadelphia, 1987, pp. $1048-1060$.

88. Jones, J.P., Engelman, E.P., Steinbach, H.L., Murray, W.R. \& Rambo, O.N. Fat embolizations a possible mechanism causing avascular necrosis. Arthritis Rheum 1965, 8: 449.

89. Fisher, D.E., Bickel, W.H. \& Holley, K.E. Histologic demonstration of fat emboli in aseptic necrosis associated with hypercortisonism. Mayo Clin Proc 1969, 44: 252-259.

90. Fisher, D.E. The role of fat embolization in the etiology of corticosteriod-induced avascular necrosis: clinical and experimental results. Clin Orthop 1978, 130: 68-80.

91. Boettcher, W.G., Bonfiglio, M., Hamilton, H.H., Sheets, R.F. \& Smith, K. Non-traumatic necrosis of the femoral head. J Bone Joint Surg 1970, 52: 312-321.

92. Fisher, D.E. \& Bickel, W.H. Corticosteroid-induced avascular necrosis. A clinical study of seventy-seven patients. $J$ Bone Joint Surg 1971, 53A: 859-873.

93. Kannel, W.B., Wolf, D.A., Castelli, W.P. \& D'Agostina, R.B. Fibrinogen and risk of cardiovascular disease. $J A M A$ 1987, 258: $1183-1186$.

94. Wilhelmsen, L., Svardsudd, K., Korsan-Bengtsen, K., Larsson, B., Welin, L. \& Tibblin, G. Fibrinogen as a risk factor for stroke and myocardial infarction. N Engl J Med 1984, 311: $501-505$.

95. Meade, T.W., Mellows, S., Brozovic, M. et al. Haemostatic function and ischaemic heart disease: principal results of the Northwick Park Study. Lancet 1986, ii: 533-537.

96. Stone, M.C. \& Thorpe, J.M. Plasma fibrinogen - a major coronary risk factor. J R Coll Gen Pract 1985, 35: 565-569.

97. Lowe, G.D.O. Blood rheology in arterial disease. Clin Sci 1985, 68: 419 .

98. Meade, T.W., North, W.R.S., Chakrabarti, R., Stirling, Y., Haines, A.P. \& Thompson, S.G. Haemostatic function and cardiovascular death: early results of a prospective study. Lancet 1980, i: 1050-1053.

99. Princen, H.M.G., Moshage, H.G., de Haard, H.J.W., van Gemert, P.L.J. \& Yap, S.H. The influence of glucocorticoid on the fibrinogen messenger RNA content of rat liver in vivo and in hepatocyte suspension culture. Biochem $J$ 1984, 220: 631-637.

100. Crane, L.J. \& Miller, J.L. Plasma protein synthesis in isolated rat hepatocytes. J Cell Biol 1977, 72: 11-25.

101. Grieninger, G., Hertzberg, K.M. \& Pindyck, J. Fibrinogen synthesis in serum-free hepatocyte cultures: stimulation by glucocorticoids. Proc Natl Acad Sci 1978, 75: 5506-5510.

102. John, D.W. \& Miller, L.L. Regulation of net synthesis of serum albumin and acute phase plasma proteins. $J$ Biol Chem. 1969, 244: 6134-6142.

103. Cain, G.D., Mayer, G. \& Jones, E.A. Augmentation of albumin but not fibrinogen synthesis by corticosteroids in patients with hepatocellular disease. J Clin Invest 1970, 49: 2198-2204.

104. Jeejeebhoy, K.N., Bruce-Robertson, A., Ho, J. \& Sodtke, U. The effect of cortisol on the synthesis of plasma albumin, fibrinogen and transferrin. Biochem J 1972, 130: 533-538.

105. Vassalli, J.-D., Hamilton, J. \& Reich, E. Macrophage plasminogen activator: modulation of enzyme production by anti-inflammatory steroids, mitotic inhibitors and cyclic nucleotides. Cell 1976, 8: 271-281.

106. Granelli-Piperno, A., Vassalli, J.-D. \& Reich, E. Secretion of plasminogen activator by human polymorphonuclear leukocytes. Modulation by glucocorticoids and other effectors. J Exp Med 1977, 146: 1693.

107. Hirata, F., Notsu, Y., Yamada, R. et al. Isolation and characterization of lipocortin. Agents Actions 1985, 17: 263-270. 
108. Moncada, S. \& Vane, J.R. Pharmacology and endogenous roles of prostaglandin endoperoxides, thromboxane $\mathrm{A} 2$ and prostacyclin. Pharmacol Rev 1979, 30: 293.

109. Gustafsson, J.-A., Carlstedt-Duke, J., Poellinger, L. et al. Biochemistry, molecular biology and physiology of the glucocorticoid receptor. Endocrin Rev 1987, 8: 185-234.

110. Kalini, M., Colman, P. \& Feigelson, P. The 'activated' hepatic glucocorticoid-receptor complex. J Biol Chem 1975, 250: $1080-1086$.

111. Baxter, J.D. \& Harris, A.W. Mechanism of glucocorticoid action: general features with reference to steroid-mediated immunosuppression. Transplantation Proc 1975, 7: 55-65.

112. Chan, L. \& O'Malley, B.W. Mechanism of action of the sex steriod hormones. N Engl J Med 1976, 294: 1372-1381.

113. Flower, R.J. \& Blackwell, G.J. Anti-inflammatory steroids induce biosynthesis of a phospholipase A2 inhibitor which prevents prostaglandin generation. Nature 1979, 278: 456.

114. Blackwell, G.J., Carnuccio, R., DiRosa, M., Flower, R.J., Parente, L. \& Persico, P. Macrocortin: a polypeptide causing the anti-phospholipase effect of glucocorticoids. Nature 1980, 287: 147.

115. Makila, U.M. The effects of betamimetics and glucocorticoids on fetal vascular prostacyclin and platelet thromboxane synthesis. Prostaglandins Leukotrienes Med 1984, 16: $11-17$.
116. Thong, K.L., Mant, M.J. \& Grace, M.G. Lack of effect of prednisone administration on bleeding time and platelet function of normal subjects. Br J Haematol 1978, 38: 373 .

117. Lewis, G.D., Campbell, W.B. \& Johnson, A.R. Inhibition of c prostaglandin synthesis by glucocorticoids in human endothelial cell. Endocrinology 1986, 119: 62-69.

118. Conn, D.L., Tompkins, R.B. \& Nichols, W.L. Glucocorticoids in the management of vasculitis - a double edged sword. J Rheumatol 1988, 15: 1181-1183.

119. Rosenfield, M.E., Tsukuda, T., Gown, M.A. \& Ross, R. Fatty streak initiation in Watanabe heritable hyperlipidaemic and comparably hypercholesterolemic fat-fed rabbits. Arteriosclerosis 1987, 1: 9-23.

120. Aqel, M.M., Ball, R.Y., Waldmann, H. \& Mitchinson, M.J. Monocyte origin of foam cells in human atherosclerotic plaques. Atherosclerosis 1984, 53: 265-271.

121. Parillo, J.E. \& Fauci, A.F. Mechanism of glucocorticoid action in immune processes. Ann Rev Pharm Tox 1979, 19: 179-201.

122. Rhinehart, J.J., Balcerzak, S.P., Sagone, A.L. \& LoBuglio, A.F. Effects of corticosteroids on human monocyte function. J Clin Invest 1974, 54: 1337-1343.

123. Rhinehart, J.J., Sagone, A.L., Balcerzak, S.P., Ackerman, G.A. \& LoBuglio, A.F. Effects of corticosteroids on human monocyte function. $N$ Engl J Med 1975, 292: 236-241. 